\title{
A phase IV, two-armed, randomized, cross-over study comparing compliance with once-a-month administration of vitamin D3 to compliance with daily administration of a fixed-dose combination of vitamin D3 and calcium during two 6-month periods
}

\author{
O. Bruyère ${ }^{1} \cdot$ R. Deroisy ${ }^{2} \cdot$ N. Dardenne ${ }^{1} \cdot$ E. Cavalier $^{3} \cdot$ M. Coffiner $^{4} \cdot$ S. Da Silva ${ }^{4}$. \\ S. De Niet $^{4} \cdot$ J.-Y. Reginster ${ }^{1}$
}

Received: 23 March 2015 / Accepted: 10 June 2015 /Published online: 23 June 2015

(C) The Author(s) 2015. This article is published with open access at Springerlink.com

\begin{abstract}
Summary In a randomized, cross-over study, once monthly administration of vitamin D3 was preferred over a once daily administration of a fixed-dose combination of vitamin D3 and calcium, with a better compliance but without any significant difference in the increase in vitamin $\mathrm{D}$ levels.

Introduction The aim of the present study was to compare a once-monthly administration of vitamin D3 to a daily administration of a fixed-dose combination of vitamin D3 and calcium during two treatment periods of 6 months.

Methods One hundred volunteers aged 50 years old or older were randomized to receive either one drinkable ampoule containing 25,000 IU vitamin D3 (D-Cure ${ }^{\circledR}$, SMB) once monthly (group VD) or one chewable tablet containing $1000 \mathrm{mg}$ calcium carbonate $+800 \mathrm{IU}$ vitamin D3 (Steovit Forte ${ }^{\circledR}$, Takeda) once daily (group VDCa) during 6 months. After the first 6 months of treatment, the groups were reversed according to the randomized cross-over design. Treatment compliance (i.e. the primary outcome), preference, acceptability and vitamin D levels and adverse events were all collected.
\end{abstract}

$O$. Bruyère

olivier.bruyere@ulg.ac.be

1 Support Unit in Epidemiology and Biostatistics, Department of Public Health, Epidemiology and Health Economics, University of Liège, Liège 4000, Belgium

2 Médecine Appareil Locomoteur, CHU Liège, BRULL, Liège, Belgium

3 Department of Clinical Chemistry, University of Liège, Liège, Belgium

4 SMB Belgium, Brussels, Belgium
Results For the two periods, the patients had a significantly higher compliance in the VD group than in the VDCa group $(p<0.0001)$. During the study, $50(56.8 \%)$ patients preferred the VD treatment, $16(18.2 \%)$ patients preferred the VDCa, and for $22(25.0 \%)$ patients, neither treatment was preferred. At the end of the first 6 months of treatment, the mean (SD) increase of $25(\mathrm{OH}) \mathrm{D}$ was $6.57 \mathrm{ng} / \mathrm{mL}(8.19)$ in the VD group and $3.88 \mathrm{ng} / \mathrm{mL}(10.0)$ in the VDCa group ( $p=0.16$ between groups).

Conclusion In this study, a once-monthly administration of vitamin D3 was preferred over a once-daily administration of a fixed-dose combination of vitamin D3 and calcium, with a better compliance but without any significant difference in the increase in vitamin D levels.

Keywords 25OHD · Compliance · Preference $\cdot$ Randomized controlled trial $\cdot$ Vitamin D

\section{Introduction}

Treatment compliance, defined as the extent to which a patient acts in accordance with the prescribed interval and dose as well as dosing regimen, is a key factor in the management of bone health, in the same way as in other chronic diseases [1]. Patient compliance improves effectiveness of osteoporosis treatment. When patients comply, there is a rise of bone mineral density, reduction of fracture risk, and improved quality of life $[1,2]$. Unfortunately, long-term compliance with treatment has been shown to be poor in osteoporosis and about half of patients stop therapy within 1 to 2 years [3]. Compliance could even be lower with supplementation with calcium 
and/or vitamin D [4]. For example, it has been suggested, in a multicentre study conducted in Spain, that only two in ten patients effectively comply with calcium and vitamin D treatment after 1 year or more of its prescription [5].

However, calcium and vitamin D are essential for the maintenance of bone homeostasis. Most of the current guidelines recommend a daily intake of calcium in postmenopausal women of at least 1000 to $1200 \mathrm{mg}$, together with at least $800 \mathrm{IU}$ of vitamin D [6, 7]. Besides its effect on falls and fractures, results from ecological, case-control and cohort studies have also shown that high vitamin D levels were associated with reduced risks of autoimmune diseases, type 2 diabetes, cardiovascular diseases and cancers [8]. Unfortunately, vitamin D status of the general population is largely below the recommended level. Indeed, it is estimated that one billion people worldwide have vitamin D deficiency or insufficiency [9].

Regarding calcium, the needs for adults are generally recognized as the intake required to maintain calcium balance and therefore skeletal integrity [10]. The Recommended Dietary Allowance (RDA) for European adults is $800 \mathrm{mg} /$ day. After menopause, the calcium requirements increase to at least $1000 \mathrm{mg} /$ day [11]. Most of the epidemiological studies suggest that calcium intake in this population is below the recommendations $[12,13]$.

Recent data suggest that there is an increased risk of incident myocardial infarction in patients taking calcium [14-16]. However, other studies or critical reviews of the literature by other groups of researchers do not support this finding [17-22]. As a consequence, the safety of calcium supplements has drawn much controversy, especially since its use is becoming more prevalent [23]. Obviously, this could also have an impact on compliance with calcium supplementation.

Another factor impacting compliance with treatment is the frequency of treatment administration [1]. In the field of bone health, pharmacological interventions, including vitamin D supplementation, have been developed with daily, weekly, monthly or multiannually regimes with the objective to improve compliance. This is particularly sensible with vitamin $\mathrm{D}$ because such an approach offers a realistic and pragmatic public health measure to target at-risk populations and addresses the emerging public health issue of widespread vitamin D insufficiency. However, still with vitamin D, dosing intervals of more than 2-3 months and/or intermittent bolus doses (200,000 IU) are not regarded as physiological and could affect clinical outcomes because of a difference in the bioavailability of vitamin $\mathrm{D}[24,25]$. The question of the ideal time between doses is, however, still of debate.

The aims of the present study are to compare the compliance with a once-monthly administration of vitamin D3 to compliance with a daily administration of a fixed-dose combination of vitamin D3 and calcium during two 6-month periods and to assess their effect on the level of vitamin $\mathrm{D}$.

\section{Material and methods}

\section{Study design}

This was a phase IV, two-armed, randomized, open, cross-over study conducted in adult volunteers aged 50 years old or older. One hundred (100) volunteers were randomized from a single investigational site in Belgium in only 4 months (October 2012-February 2013). After the screening visit (month 0), volunteers respecting all inclusion/exclusion criteria were divided into two groups of treatment. One hundred volunteers were randomized to receive either one drinkable ampoule containing 25,000 IU vitamin D3 once monthly (i.e. group VD) or one chewable tablet containing $1000 \mathrm{mg}$ calcium carbonate +800 IU vitamin D3 once daily (i.e. group VDCa) during 6 months. After the first 6 months of treatment, the groups were reversed and each volunteer received the other treatment for another period of 6 months according to the cross-over design. Volunteers were asked to come to the investigator site for three visits, during the study period: month 0 , month 6 and month 12 .

\section{Subjects}

Male and female subjects 50 years old or older with a body mass index (BMI) between 18 and $35 \mathrm{~kg} / \mathrm{m}^{2}$ were included in this study. Volunteers who met any of the following criteria were excluded from participating in the study: use of drugs which may interfere with vitamin D metabolism (e.g. phenobarbital, phenytoin and oral and parenteral glucocorticoids), use of any vitamin D supplement alone or in association (i.e. multivitamin, vitamin $\mathrm{D} /$ calcium combination or vitamin $\mathrm{D} /$ biphosphonate combination) within 4 weeks before the screening visit; UV light solarium was used 2 weeks before the screening visit and during the study.

All subjects provided written, informed consent to participate in the study, indicated by a personal signature and date on the volunteer consent form.

\section{Assessments}

At screening (T0), demographics, medical history, previous and concomitant medications, and vitamin D status were all evaluated. Moreover, instructions for drug administration were given. After 6 months, concomitant medications, adverse events, compliance, persistence, treatment acceptability and vitamin D status were also evaluated. At the end of the study (T12), concomitant medications, compliance, persistence, adverse events and treatment acceptability were again evaluated. A questionnaire about the preferred treatment was also submitted to the patients. 
The following procedures were observed:

- Treatment compliance (i.e. the primary outcome): calculated as the number of tablets/ampoules taken by the patient divided by the number of tablets/ampoules to be taken for a given period of time

- Vitamin D status: the level of 25(OH)D level was assessed with the DiaSorin Liaison assay (Saluggia, Italy). In our procedure, the $\mathrm{CV}$ was $<8 \%$.

- Treatment preference: a questionnaire assessing the possible preference of the subject for one of the treatments was given to all subjects. The reason, including taste, ease of use, frequency of use, number of adverse events, reputation of the treatment, was also asked.

- Treatment acceptability: overall satisfaction was assessed by a questionnaire. More specific questions on taste, ease of use, frequency of use and occurrence of adverse events were also asked.

- Adverse events (AEs): the number of events, but also the number of patients, with emergent AEs, treatment-related AEs, severe AEs, severe and treatment-related AEs, serious AEs (SAEs), treatment-related SAEs, withdrawals due to AEs and withdrawals due to treatment-related AEs were reported.

\section{Statistical analysis}

The Shapiro-Wilk test was utilized to test if population distribution was normally distributed or not. Quantitative variables were expressed by mean, standard deviation (SD) or median and interquartile range (P25-P75) for asymmetric distributions. Qualitative variables were expressed by number and percentage. For quantitative variables, comparison between the two groups of treatment was assessed by means of a Student $t$ test for independent populations or a non-parametric Mann-Whitney test if normality was not satisfied. The relationship between qualitative variables and group of treatment was assessed using a chi ${ }^{2}$ test. As the study design was a crossover study, compliance was analyzed according to the method described in D. G. Altman ("Statistical methods for medical research", Chapman and Hall, London, 1991). This method consists of testing a period/sequence effect, then an interaction effect between period and treatment, and finally, and only in case of no significant effect of period and interaction, a treatment effect. All effects are assessed by using a two-sample $t$ test or a non-parametric test of Mann-Whitney. To test the mean evolution of vitamin D between $\mathrm{T} 0$ and $\mathrm{T} 6$ within the two treatment groups, a Student $t$ test for independent samples was used. The relationship between the main reasons of preference to a treatment and the chosen treatment was assessed by a Fisher exact test. For each criterion of acceptability (taste, ease of use, frequency of use, AEs and overall satisfaction), the categories 'not at all satisfied', 'slightly satisfied' and 'moderately satisfied' were regrouped due to few data. For the same reason, the categories 'very much satisfied' and 'extremely satisfied' were also regrouped. For each acceptability criterion, the degree of satisfaction for the two treatments was compared by means a McNemar test. Results were considered to be statistically significant at the $5 \%$ critical level $(p<0.05)$. Data analysis was carried out using SAS (version 9.3 for Windows) and R (version 2.15) statistical packages.

\section{Results}

The first patient was randomized on October 15, 2012. A total of 100 patients were enrolled over 4 months (last randomization date February 14, 2013). The last visit took place on February 17, 2014.

At baseline (T0), no significant differences were found in any of the characteristics between the two groups of patients (Table 1).

For the two periods, the compliance was higher in the VD group than in the VDCa group $(p<0.0001)$, and the greatest difference in compliance rate was observed for patients who changed from the VDCa group to the VD group. In both periods 1 and 2, the compliance in the VD group was $100 \%$ (P25-P75 100-100) but was 96.2\% (83.1-100) and 91.7\% (76.9-96.8) for the VDCa group, in periods 1 and 2, respectively.

During the study, 50 (56.8\%) patients preferred the VD treatment, $16(18.2 \%)$ patients preferred the VDCa treatment and, for $22(25.0 \%)$ patients, neither treatment was preferred. Interestingly, the treatments were chosen for different reasons $(p=0.030$, Table 2$)$. The main reason given by patients who preferred the VD treatment was the frequency of use (42\%), while VDCa was mainly chosen for its ease of use $(62.4 \%)$.

Proportions of patients who were 'not at all satisfied' to 'moderately satisfied' were different depending on the treatment for the following acceptability criteria: (1) frequency of

Table 1 Baseline characteristics for the two groups of treatment

\begin{tabular}{llll}
\hline Variable & Group 1 $(n=50)$ & Group 2 $(n=49)$ & $p$ value \\
\hline $\begin{array}{l}\text { Age (years) } \\
\text { Median (P25-P75) }\end{array}$ & $65.5(57.4-72.7)$ & $67.5(61.2-73.8)$ & 0.38 \\
$\begin{array}{l}\text { Weight }(\mathrm{kg}) \\
\text { Mean } \pm \mathrm{SD}\end{array}$ & $69.8 \pm 12.3$ & $72.2 \pm 12.3$ & 0.34 \\
Height $(\mathrm{cm})$ & $160.9 \pm 7.77$ & $164.2 \pm 8.73$ & 0.054 \\
BMI $\left(\mathrm{kg} / \mathrm{m}^{2}\right)$ & $26.9 \pm 4.10$ & $26.7 \pm 3.76$ & 0.82 \\
25OHD $(\mathrm{ng} / \mathrm{mL})$ & $29.7 \pm 11.2$ & $27.6 \pm 10.1$ & 0.34 \\
Gender & & & \\
$\quad$ Male & $14(28.0)$ & $13(26.5)$ & 0.87 \\
$\quad$ Female & $36(72.0)$ & $36(73.5)$ & \\
\hline
\end{tabular}


Table 2 Association between chosen reasons of preference and chosen treatment

\begin{tabular}{llcll}
\hline & VD group & VDCa group & $\begin{array}{l}\text { Fisher exact } \\
\text { test } \\
p\end{array}$ \\
& & $N(\%)$ & $N(\%)$ & 0.030 \\
\hline Reason & Taste & $2(3.0)$ & $3(18.8)$ & \\
& Ease of use & $17(34.0)$ & $10(62.4)$ & \\
& Frequency of use & $21(42.0)$ & $3(18.8)$ & \\
No adverse events & $7(14.0)$ & $0(0.0)$ & \\
Treatment reputation & $0(0.0)$ & $0(0.0)$ & \\
Other & $3(6.0)$ & $0(0)$. & \\
Total & $50(76.5)$ & $16(23.5)$ & \\
\hline
\end{tabular}

use ( $p=0.0023)$ and (2) adverse events $(p=0.0010)$, patients being less satisfied when taking VDCa treatment. No difference was found for taste and ease of use criteria. When acceptability criteria were considered as continuous variables, satisfaction was higher with VD treatment for the following acceptability criteria: (1) frequency of use $(p=0.010),(2)$ adverse events $(p=0.0034)$ and (3) overall satisfaction $(p<0.0001)$ (Table 3).

During the first 6 months of follow-up, the mean (SD) 25(OH)D increased from $29.1 \mathrm{ng} / \mathrm{mL}$ (10.9) to $35.7 \mathrm{ng} / \mathrm{mL}$ (8.85) in the VD group and from $27.9 \mathrm{ng} / \mathrm{mL}(10.2)$ to $31.8 \mathrm{ng} / \mathrm{mL}(8.8)$ in the VDCa group, without any statistical differences between groups $(p=0.16)$.

The incidence of adverse events related to treatment was low but more frequently reported by subjects on VDCa (Table 4).These adverse events related to treatment were gastrointestinal disorders (i.e. constipation, nausea and abdominal upper pain).

\section{Discussion}

Strategies to improve patient compliance are of primary importance. Many interventions, involving different factors, may be considered. Indeed, there is evidence to support that a multifaceted strategy targeting cognitive, behavioural and emotional factors is more effective than one aimed at a single factor [26]. Preference of the patients also needs to be taken into account [27]. Indeed, besides the potential effect on compliance with treatment, the patient's perspective is becoming increasingly important in clinical and policy decisions. In our study, more patients preferred D-Cure ${ }^{\circledR}$, but the two treatments (i.e. D-Cure ${ }^{\circledR}$ and Steovit Forte ${ }^{\circledR}$ ) were chosen for different reasons. The frequency of use is the main reason given for choosing vitamin $\mathrm{D}$ alone, but it should be pointed that the potential reasons for preference were predefined.

Interestingly, increasing time between two doses has also been suggested to improve compliance. However, and more globally, the dose interval is still a matter of debate. On one side, some studies have suggested that compliance with monthly regimes could be better than with daily regimes [1]. On the other side, according to a recent review, it is likely that for the optimal functioning of the endocrine/autocrine system, significant $25 \mathrm{OHD}$ should be available on a daily basis to ensure stable circulating concentrations, implying that variation in vitamin $\mathrm{D}$ dosing schedules could have profound effects on the outcomes of clinical trials because of the short circulating half-life of intact vitamin D [24]. Consequently, the balance between bioavailability and compliance needs to be taken into account.

Anyway, it should be pointed out that although the exact consequences of dose interval on bone health outcome are not well known, the effect of the frequency of vitamin D administration on vitamin D status has already been investigated. In our study, even if the monthly intake has improved the vitamin D status more than the daily intake, it does not reach statistical significance. Other studies have compared daily, weekly and monthly vitamin D supplementation. In one 4-month study of equivalent oral doses of vitamin D3 $600 \mathrm{IU} /$ day, $4200 \mathrm{IU} /$ week and 18,000 IU/month, daily dosing was the most and monthly dosing the least effective to raise $25(\mathrm{OH}) \mathrm{D}$ concentrations [28]. In another 2-month study, intakes of $1500 \mathrm{IU}$ of D3 daily, 10,500 IU weekly and 45,000 IU once every 28 days were equally effective [29]. In a 1-year study, intakes of $800 \mathrm{IU}$ daily were more efficient than intakes of 97,333 IU every 4 months to increase serum 25(OH)D3 concentrations [30]. Another study, conducted over a period of 3 months, showed no difference in the improvement of vitamin D status
Table 3 Association between acceptability criteria considered as continuous variables and treatment

\begin{tabular}{lllllll}
\hline Acceptability & \multicolumn{2}{l}{ VD group $(n=87)$} & & \multicolumn{2}{l}{ VDCa group $(n=87)$} & Non-parametric $p$ \\
\cline { 2 - 3 } & Mean $\pm \mathrm{SD}$ & $\mathrm{M}(\mathrm{P} 25-\mathrm{P} 75)$ & & Mean $\pm \mathrm{SD}$ & $\mathrm{M}(\mathrm{P} 25-\mathrm{P} 75)$ & \\
\hline Taste & $3.59 \pm 0.97$ & $4(3-4)$ & & $3.69 \pm 0.89$ & $4(3-4)$ & 0.46 \\
Ease of use & $4.06 \pm 0.64$ & $4(4-4)$ & & $4.06 \pm 0.70$ & $4(4-4)$ & 0.95 \\
Frequency of use & $4.06 \pm 0.57$ & $4(4-4)$ & & $3.77 \pm 0.83$ & $4(3-4)$ & 0.010 \\
Adverse events & $4.24 \pm 0.63$ & $4(4-5)$ & & $3.90 \pm 1.06$ & $4(4-5)$ & 0.0034 \\
Overall satisfaction & $2.91 \pm 0.29$ & $3(3-3)$ & & $2.63 \pm 0.65$ & $3(2-3)$ & $<0.0001$ \\
\hline
\end{tabular}


Table 4 Summary table of adverse events for the safety population

\begin{tabular}{lccccc}
\hline & \multicolumn{2}{l}{ VD group } & & \multicolumn{2}{l}{ VDCa group FORTE } \\
\cline { 2 - 3 } \cline { 5 - 6 } & $N(\%)$ of patients & N of events & & $N(\%)$ of patient & $N$ of events \\
\hline Emergent AEs & $54(54.5)$ & 102 & & $58(58.6)$ & 107 \\
Treatment-related AEs & $4(4.04)$ & 10 & & $10(10.1)$ & 11 \\
Serious AEs & $6(6.06)$ & 8 & & $6(6.06)$ & 7 \\
Treatment-related serious AEs & 0 & 0 & & $3(3.03)$ & 0 \\
Withdrawals due to AEs & $1(1.01)$ & 1 & & $2(2.02)$ & 3 \\
Withdrawals due to & 0 & 0 & & & 2 \\
\multicolumn{1}{c}{ treatment-related AEs } & & & & \\
\hline
\end{tabular}

between supplementations of $2000 \mathrm{IU} /$ day or $60,000 \mathrm{IU} /$ month [31].

It should also be noted that even if most of the epidemiological studies suggest that the prevalence of adequate calcium intake is low, the supplementation of calcium is not necessary in subjects with sufficient intake of calcium from food. Indeed, the best way to meet the daily dietary calcium requirement is through the intake of foods high in calcium: such as dairy products, green vegetables, and mineral waters [10]. Dairy products may represent one of the best dietary sources of calcium as they provide more calcium (and protein, magnesium, potassium, zinc and phosphorus) per calorie than any other typical food found in the adult diet [32]. The recommended consumption is three portions of dairy products per day (for example, one glass of milk, one portion of cheese and one yogurt). This amount could provide most of the calcium needs of the general population and could limit the use or the dose of calcium supplementation in the elderly. Another possibility to improve calcium intake, keeping a once-monthly intake of vitamin D, would be with food fortification. A variety of calcium-fortified foods, such as orange juice and soy milk, are available in some countries and provide the same amount of calcium as dairy products. Interestingly, it has been calculated, from the FINDIET data, that calcium fortification of only $11 \%$ of all fortifiable foods would lead to a decrease of the proportion of participants with calcium intake below the recommended level from 20.3 to $15.7 \%$ in men and from 27.8 to $23.2 \%$ in women [33].

We should acknowledge that besides the open-label design of this study, a major limitation of this study is that no daily calcium supplementation was given to the subjects from the monthly dose of the vitamin D group. Obviously, the wellknown minor adverse events (e.g. gastrointestinal disorders) observed with calcium supplementation could have affected the compliance with the combined calcium/vitamin D product that, in turn, could have influenced the vitamin D status.
However, because of the controversies regarding calcium supplementation, some prescribers and some patients could be willing to avoid such supplementation. In these circumstances, strategies to increase calcium intake through calcium-fortified food should be activated.

On the other side, in Belgium, where this study was conducted, there is no other supplement than D-Cure ${ }^{\circledR}$ containing cholecalciferol alone. All specialities containing cholecalciferol are combined with calcium. Steovit Forte ${ }^{\circledR}$ was chosen, as the dose of cholecalciferol ( $800 \mathrm{IU} /$ daily) is the closest to that of D-Cure ${ }^{\circledR}(25.000 \mathrm{IU} /$ month). It should then be pointed out that the monthly total dose of vitamin D3 delivered in the monthly supplement was 1000 IU greater than in the daily supplement. The cost per month is $1.25 €$ for $\mathrm{D}-\mathrm{Cure}^{\circledR}$ and $15.87 €$ for Steovit Forte ${ }^{\circledR}$. In our study, a substantial proportion of the volunteers were previously treated with D-Cure ${ }^{\circledR}$ and/or Steovit Forte ${ }^{\circledR}$. Therefore, both products were well known by the volunteers before their entry in the study. In addition, both products are available on the Belgium market since many years and without prescription over the counter.

In conclusion, our study demonstrated that a monthly dose of vitamin $D$ is preferred to a daily combined administration of calcium and vitamin D and leads to a better compliance but without a significant difference in serum vitamin D concentration between both regimes/treatments.

Acknowledgments This study was supported by a grant from Laboratoires SMB, a pharmaceutical company in Belgium who manufactures the D-Cure ${ }^{\mathbb{R}}$.

Conflicts of interest $\mathrm{RD}$ and $\mathrm{ND}$ have no competing interest. $\mathrm{OB}$ has received grants or fees for research from GlaxoSmithKline, IBSA, Merck Sharp \& Dohme, Theramex, Novartis, Pfizer, Rottapharm, Servier and SMB.EC is a consultant for DiaSorin and IDS and has received lecture fees from IDS, DiaSorin, Roche, Abbott, Pfizer and Amgen. JYR has received consulting fees, paid advisory boards, lecture fees, and/or grant support from Servier, Novartis, Negma, Lilly, Wyeth, Amgen, GlaxoSmithKline, Roche, Merckle, Nycomed, NPS, Theramex, UCB, Merck Sharp \& Dohme, Rottapharm, IBSA, Genevrier, Teijin, Teva, Ebewee Pharma, Zodiac, Analis, Novo Nordisk, and Bristol-Myers Squibb. MC, SDS, SDN are employed by SMB 
Open Access This article is distributed under the terms of the Creative Commons Attribution-NonCommercial 4.0 International License (http:// creativecommons.org/licenses/by-nc/4.0/), which permits any noncommercial use, distribution, and reproduction in any medium, provided you give appropriate credit to the original author(s) and the source, provide a link to the Creative Commons license, and indicate if changes were made.

\section{References}

1. Silverman S, Gold DT (2010) Compliance and persistence with osteoporosis medications: a critical review of the literature. Rev Endocr Metab Disord 11(4):275-280

2. Rabenda $\mathrm{V}$ et al (2008) Adherence to bisphosphonates therapy and hip fracture risk in osteoporotic women. Osteoporos Int 19(6):811818

3. Rabenda V, Hiligsmann M, Reginster JY (2009) Poor adherence to oral bisphosphonate treatment and its consequences: a review of the evidence. Expert Opin Pharmacother 10(14):2303-2315

4. Diez A et al (2012) Observational study of treatment compliance in women initiating antiresorptive therapy with or without calcium and vitamin D supplements in Spain. Menopause 19(1):89-95

5. Castelo-Branco C, Cortes X, Ferrer M (2010) Treatment persistence and compliance with a combination of calcium and vitamin D. Climacteric 13(6):578-584

6. Rizzoli R et al (2013) Vitamin D supplementation in elderly or postmenopausal women: a 2013 update of the 2008 recommendations from the European Society for Clinical and Economic Aspects of Osteoporosis and Osteoarthritis (ESCEO). Curr Med Res Opin 29(4):305-313

7. van der Velde RY et al (2014) Calcium and vitamin D supplementation: state of the art for daily practice. Food Nutr Res 58

8. Bruyere O et al (2014) Effects of vitamin D in the elderly population: current status and perspectives. Arch Public Health 72(1):32

9. Holick MF (2006) Resurrection of vitamin D deficiency and rickets. J Clin Invest 116(8):2062-2072

10. Rizzoli R (2014) Nutritional aspects of bone health. Best Pract Res Clin Endocrinol Metab 28(6):795-808

11. Kanis JA et al (2013) European guidance for the diagnosis and management of osteoporosis in postmenopausal women. Osteoporos Int 24(1):23-57

12. Bruyere O et al (2009) Low dietary calcium in European postmenopausal osteoporotic women. Public Health Nutr 12(1):111-114

13. Czernichow $\mathrm{S}$ et al (2010) Calcium and vitamin $\mathrm{D}$ intake by postmenopausal women with osteoporosis in France. Curr Med Res Opin 26(7):1667-1674

14. Lewis JR, Zhu K, Prince RL (2012) Adverse events from calcium supplementation: relationship to errors in myocardial infarction self-reporting in randomized controlled trials of calcium supplementation. J Bone Miner Res 27(3):719-722

15. Bolland MJ et al (2010) Effect of calcium supplements on risk of myocardial infarction and cardiovascular events: meta-analysis. BMJ 341:c3691

16. Bolland MJ et al (2011) Calcium supplements with or without vitamin D and risk of cardiovascular events: reanalysis of the
Women's Health Initiative limited access dataset and meta-analysis. BMJ 342:d2040

17. Rojas-Fernandez $\mathrm{CH}$ et al (2012) Assessing the potential adverse consequences of supplemental calcium on cardiovascular outcomes: should we change our approach to bone health? Ann Pharmacother 46(5):696-702

18. Prentice RL et al (2013) Health risks and benefits from calcium and vitamin D supplementation: Women's Health Initiative clinical trial and cohort study. Osteoporos Int 24(2):567-580

19. Rautiainen $\mathrm{S}$ et al (2013) The role of calcium in the prevention of cardiovascular disease-a review of observational studies and randomized clinical trials. Curr Atheroscler Rep 15(11):362

20. Challoumas D et al (2014) Effects of combined vitamin D - calcium supplements on the cardiovascular system: should we be cautious? Atherosclerosis 238(2):388-398

21. Wang $L$ et al (2010) Systematic review: vitamin D and calcium supplementation in prevention of cardiovascular events. Ann Intern Med 152(5):315-323

22. Heaney RP et al (2012) A review of calcium supplements and cardiovascular disease risk. Adv Nutr 3(6):763-771

23. Zittermann A et al (2011) Calcium supplementation and vitamin D: a trigger for adverse cardiovascular events? Future Cardiol 7(6): 725-727

24. Hollis BW, Wagner CL (2013) Clinical review: the role of the parent compound vitamin D with respect to metabolism and function: why clinical dose intervals can affect clinical outcomes. J Clin Endocrinol Metab 98(12):4619-4628

25. Sanders KM, Nicholson GC, Ebeling PR (2013) Is high dose vitamin D harmful? Calcif Tissue Int 92(2):191-206

26. Trevisan C (2011) Secondary prevention of fractures and compliance to treatment in osteoporosis. Aging Clin Exp Res 23(2 Suppl): $22-24$

27. Reginster JY, Rabenda V (2006) Patient preference in the management of postmenopausal osteoporosis with bisphosphonates. Clin Interv Aging 1(4):415-423

28. Chel V et al (2008) Efficacy of different doses and time intervals of oral vitamin D supplementation with or without calcium in elderly nursing home residents. Osteoporos Int 19(5):663-671

29. (2008) Comparison of daily, weekly, and monthly vitamin D3 in ethanol dosing protocols for two months in elderly hip fracture patients. J Clin Endocrinol Metab 93(9):3430-3435

30. Pekkarinen T et al (2010) The same annual dose of $292000 \mathrm{IU}$ of vitamin $\mathrm{D}$ (cholecalciferol) on either daily or four monthly basis for elderly women: 1-year comparative study of the effects on serum 25(OH)D concentrations and renal function. Clin Endocrinol (Oxf) 72(4):455-461

31. Saadi HF et al (2007) Efficacy of daily and monthly high-dose calciferol in vitamin D-deficient nulliparous and lactating women. Am J Clin Nutr 85(6):1565-1571

32. Bonjour JP et al (2013) Dairy in adulthood: from foods to nutrient interactions on bone and skeletal muscle health. J Am Coll Nutr 32(4):251-263

33. Hirvonen $\mathrm{T}$ et al (2006) Efficacy and safety of food fortification with calcium among adults in Finland. Public Health Nutr 9(6): 792-797 